\title{
Effect of Infilled Panel on the Nonlinear Dynamic Response of Reinforced Concete Plane Frames
}

\author{
Mohammad N. Mahmood \\ Assistant Professor \\ Civil Engineering Department \\ Mosul University/Iraq
}

\author{
Saddam, M. Ahmed \\ Assistant Lecturer \\ Water Resources Department \\ Mosul University/Iraq
}

\begin{abstract}
Studying the effects of the static and dynamic loads on structures is very essential, especially in zones where the structures are exposed to severe earthquakes. In the present study a finite element program is developed for static and dynamic analysis of reinforced concrete plane frames. The main concern is to study the effects of infilled panels on the behavior of this type of structure. One dimensional Beam-Column Elements are used to represent the frame members and Lumped Plasticity Model is used to model the nonlinearity of these elements. Modified Four-node isoparametric plane stress elements with 3-DOF per node, are used to represent infilled panels. Connection between infill element and frame is either assumed to be perfect or by linkage elements which allow separation between the two types of elements. Two programs are developed one for the static and the other for the dynamic analysis and the validity of the developed programs have been checked and the predicted results indicated a good agreement with the published experimental and theoretical results.
\end{abstract}

Keywords: dynamic, finite element, frame, linkage, interface.
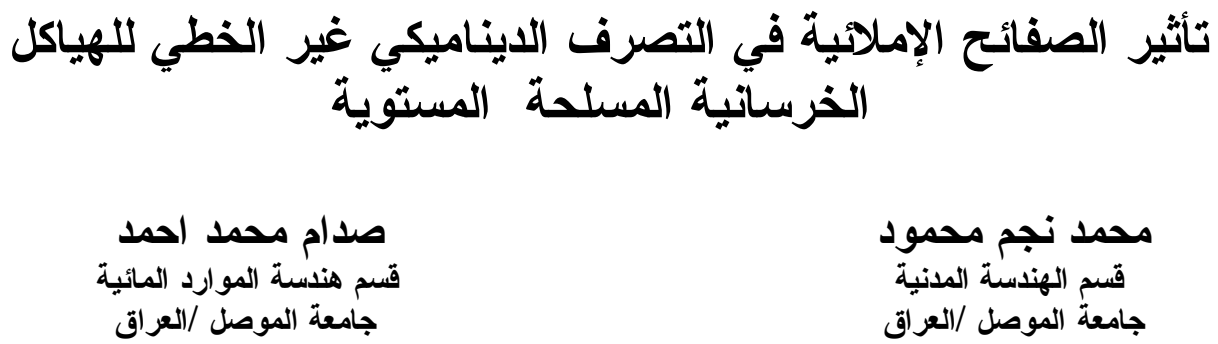

الخلاصة

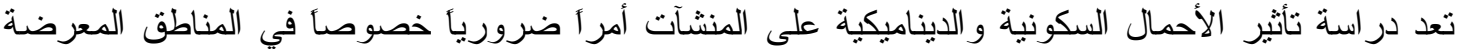

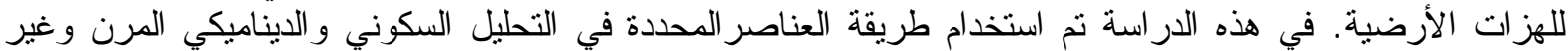

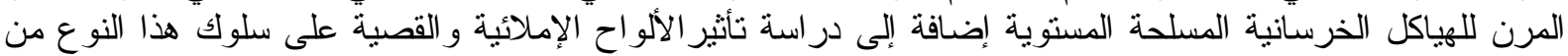

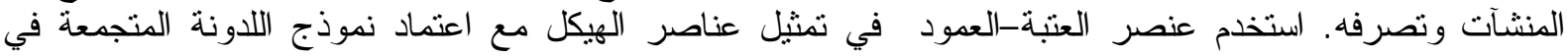

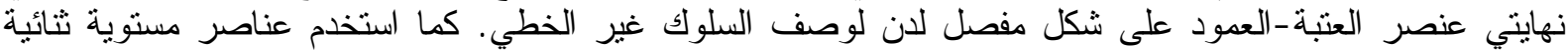

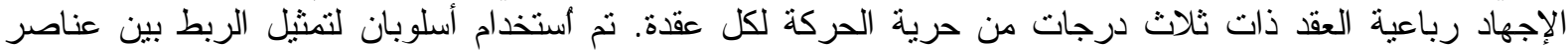

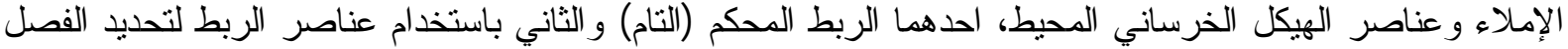

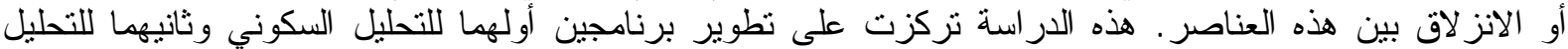

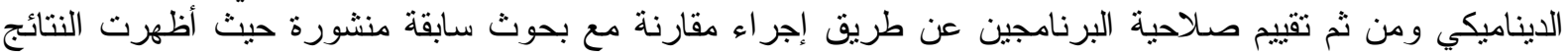
تقاربأ جيدأ مع نتائج البحوث و الدر اسات السابقة. 


\section{Introduction}

Reinforced concrete frame buildings often incorporate masonry infill panels as partitions to separate spaces within a building or as cladding to complete the building envelope. Quite often, limited works are done to take advantage of, or to recognize the shear strengthening effects of these panels. However, the properties and construction details of infilled panels can have a significant influence on the overall behavior of a structure. Despite the large amount of works and information that are available about the potential economy and efficiency of infilled frames, structural engineers are often neglecting the infills in the analysis of framed structures.

The complex interaction between the infill and surrounding structural frame was identified in earlier work conducted by Polyakov [1]. Some researchers have studied systems consisting of various combinations of frame and infill materials (Seah and Dawe)[2]. The contribution of masonry infilled panels to the lateral stiffness and strength of reinforced concrete frames has been documented in many research publications (Mehrabi and Shing)[3]. Plastic design principles were proposed by Wood [4] to estimate the ultimate lateral load resistance of infilled frames with modification, these methods may be used to determine the elastic and inelastic load responses of simple structures. The present paper deals with developing a finite element program that is capable of taking into consideration the nonlinear dynamic analysis of infill reinforced concrete plane frame taking into consideration the effects of interface between the frame elements and infilled elements.

\section{Finite Element Idealization}

In the present study, reinforced concrete infilled frame has been analyzed by using the finite element method to model the skeleton frame, the panels and the linkage elements that connect the panel element with the surrounding frame. The frame was modeled by a 2-noded frame element (beam-column), while the infill panel was modeled by 4-noded isoparamatric elements. The connection between these two types of elements is either perfect by assigning the same node number or by linkage elements as shown in Fig.(1).

\section{1: Reinforced Concrete Frame Element}

Two dimensional beam-column elements are used to model the frame members as shown in Fig.(1). Each element has 2-nodes with (3DOF) $\left(u, v, \theta_{z}\right)$ at each node. Lumped plasticity is used to model the nonlinearity of this element, this is achieved by assuming that plastic hinges develop at the ends of the element. The extension of the analysis of reinforced concrete structures for inelastic dynamic response requires modeling the inelastic response of the reinforced concrete elements which includes nonlinear stress-strain relation of concrete, strain rate effect and concrete confinement effects. The inelastic behaviour of reinforced concrete beam-column element requires the simulation of the interaction between axial forces and bending moments. In the present study the effect of interaction between these forces is considered in developing the yield surface for each element. This yield function is based on a nonlinear stress stain relationship in the form of fourth order polynomial as proposed by Medland and Taylor [5], which can be expressed as follows:

$$
\sigma_{c}=f_{c}^{\prime}\left(A \cdot \varepsilon_{c}^{4}+B \cdot \varepsilon_{c}^{3}+C \cdot \varepsilon_{c}^{2}+D \cdot \varepsilon_{c}\right)
$$

Where $\left(\sigma_{\mathrm{c}}\right)$ is the stress in concrete corresponding to strain $\left(\varepsilon_{\mathrm{c}}\right)$, constants $(\mathrm{A}, \mathrm{B}, \mathrm{C}$ and D) are the coefficients of the polynomial, and $\left(f_{c}\right)$ represents the ultimate compressive strength of concrete. 
Steel reinforcement (main reinforcement only) is assumed to behave as elastic or elastoplastic with strain hardening.

$\sigma_{s}=E_{s} \cdot \varepsilon_{s} \quad \sigma_{s} \leq f_{y}$
$\sigma_{s}=f_{y+} E_{s t} \cdot\left(\varepsilon_{s}-\varepsilon_{y}\right) \quad \sigma_{s}>f_{y}$

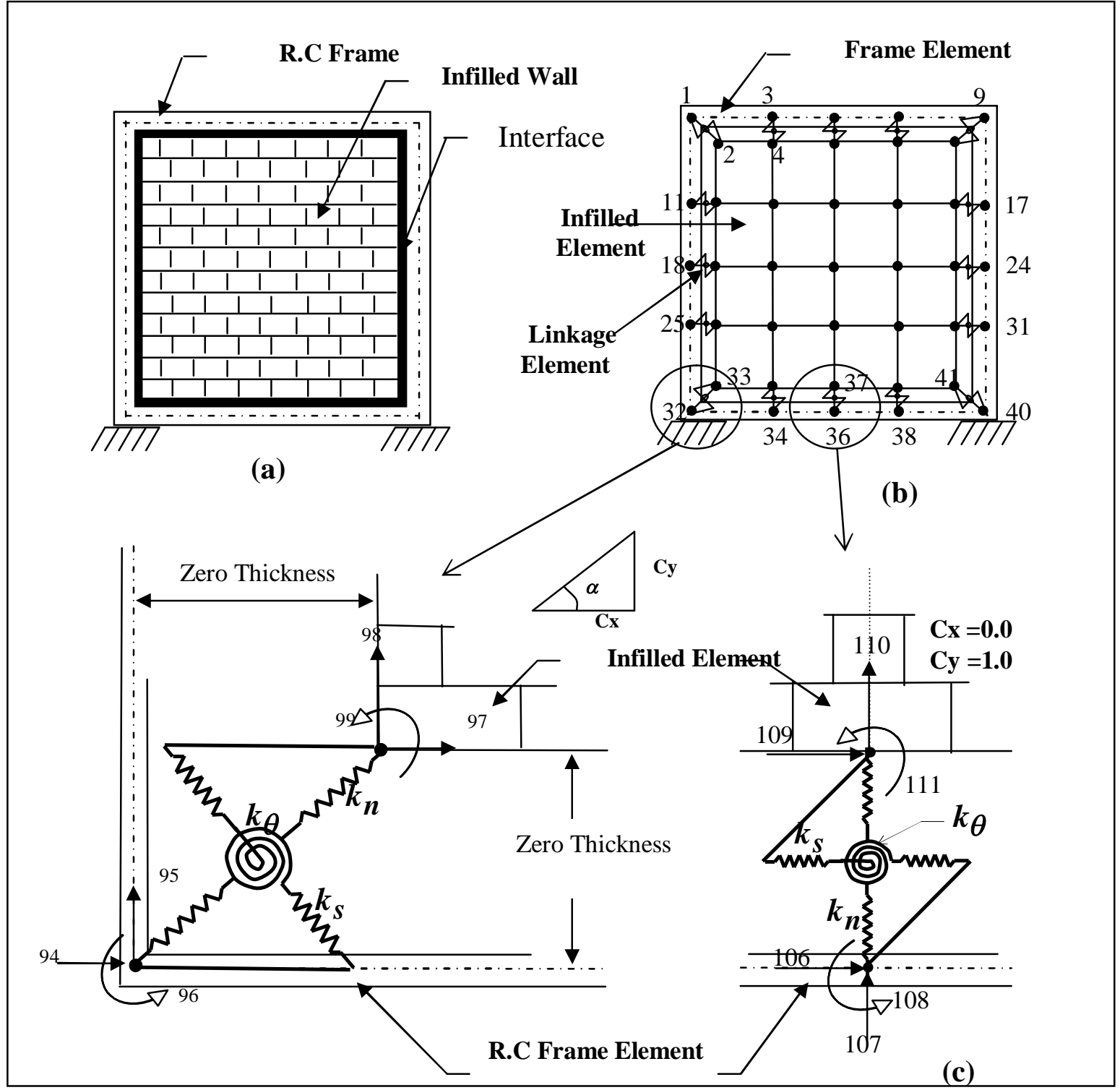

Fig.(1):Different elements used for modeling the infilled frame

$\left(E_{s}\right)$ is the modulus of elasticity of steel, $\left(E_{s t}\right)$ is the slope of the strain-hardening portion of steel stress-strain curve, $\left(f_{y}\right)$ the yield stress and $\left(\varepsilon_{y}\right)$ is the yield strain.

The following basic assumptions are made while analyzing any $\mathrm{R} / \mathrm{C}$ section:

$>$ The stress-strain relations for concrete and steel are known and these are closely represented by the corresponding uniaxial stress-strain relations. These relations are also independent of the geometry of the member.

$>$ Tensile strength of concrete is negligible.

$>$ The section which is plane before bending remains plane after bending.

$>$ Perfect bond between steel and concrete. 
Each member has a uniform rectangular cross-section throughout its length with symmetrical reinforcement.

A yield surface for a reinforced concrete section subjected to simultaneous action of bending moment and axial force is evolved in the form [6,7, and 8].

$$
\frac{m_{u}}{m_{\circ}}=a_{1}+a_{2} \cdot\left(\frac{p_{u}}{p_{\circ}}\right)+a_{3} \cdot\left(\frac{p_{u}}{p_{\circ}}\right)^{2}+a_{4} \cdot\left(\frac{p_{u}}{p_{\circ}}\right)^{3}
$$

Where $\left(m_{u}\right)$ is the ultimate moment corresponding to the ultimate axial load $\left(p_{u}\right)$, while a1, $\mathrm{a} 2$, a3, and a4 are the polynomial constants to be determined by the least square method, $\left(\mathrm{p}_{0}\right.$, $\mathrm{m}_{0}$ ) is the nondimensional ultimate axial force and bending moment which both may be written as:

$m_{o}=\frac{M_{o}}{b \cdot d^{2} \cdot f_{c}^{\prime}} \quad, \quad p_{o}=\frac{P_{o}}{b \cdot d \cdot f_{c}^{\prime}}$

Where $\left(\mathrm{M}_{0}\right)$ is the uniaxal flexural strength of the cross section in the absences of axial load. With the help of Eq.(3). The following equation defines the yield function:

$$
f=\left|\frac{m}{m_{u}}\right|=1.0
$$

The analysis starts by assuming an elastic behaviour, then the resulting end forces are checked against the yield surface. If the point lies on or outside the failure surface, a plastic hinge is assumed to develop at that point. Theory of plasticity has been used to calculate the inelastic deformation and elasto-plastic stiffness and unbalanced forces of the members. These unbalanced forces are then applied to the structure taking into account physical changes due to formation of plastic hinges. The stiffness matrix is modified after each new occurrence of plastic hinge(s) and it is assumed to remain unchanged until another hinge(s) is developed.

\section{2: Brick masonry infill:}

A 4-noded isoparametric element, shown in Fig.(2) is used to model the infill masonry panels, the material of the infill is a non-homogeneous material consisting of assemblage of bricks and mortar joints, each having different properties. The complexity of modeling the masonry wall is due to the mortar joints that act as planes of weakness due to their low tensile, shear and bond strengths. In the present study these planes of weakness are neglected, and the infill panels are considered as a homogeneous material.

\section{a) Drilling degree stiffness matrix}

To achieve compatibility in the degrees of freedom of the infilled elements (plane stress) and frame elements (beam-column), a drilling degree of freedom is added to the original plane stress elements as follows:

The displacement and forces can be defined as:

$$
\begin{aligned}
& \left\{u_{m i}\right\}=\vec{u}_{m i}=\left[\begin{array}{lll}
u_{i} & v_{i} & \theta_{z i}
\end{array}\right]^{T} \\
& \left\{P_{m i}\right\}=\vec{P}_{m i}=\left[\begin{array}{lll}
P_{x i} & P_{y i} & M_{z i}
\end{array}\right]^{T}
\end{aligned}
$$

Where $\{\vec{u}\}$ and $\left\{\vec{P}_{m i}\right\}$ are deformations and forces corresponding to node (i) as shown in Fig(3), the strain-displacement sub matrix for node (i) may be written as: 
$\left[B_{i}\right]=\left[\begin{array}{ccc}\frac{\partial N_{i}}{\partial x} & 0 & 0 \\ 0 & \frac{\partial N_{i}}{\partial y} & 0 \\ \frac{\partial N_{i}}{\partial y} & \frac{\partial N_{i}}{\partial x} & 0\end{array}\right]$

And the stiffness matrix of the 4-noded element calculated from the following equation:

$$
\begin{aligned}
& {\left[K_{c}\right]=\int_{v o l}[B]^{T}\left[D_{e}\right][B] d v} \\
& {\left[K_{c}\right]=h \int_{-1}^{+1} \int_{-1}^{+1}[B]^{T}\left[D_{e}\right] \quad[B]|J| d r d s}
\end{aligned}
$$

Where $\left(D_{e}\right)$ is material property matrix based on the state of stress at the Gauss point. And $(h)$ is the thickness of the element. $|\mathrm{J}|$ is determinate of the Jacobian matrix. The dimension of resulting stiffness matrix is $(12 * 12)$ with the values in rows and columns corresponding to the drilling degrees of freedom $\left(\boldsymbol{\theta}_{z i}\right)$ are all zero. The following steps illustrate the adopted procedure which is used to calculate the stiffness coefficients related to the drilling degrees of freedom.

A fictitious torsional spring along the local normal direction at each node is assumed.

- The rotation of the normal and the mid surface displacement field are independent. As shown in Fig.(3) the rotation of the mid surface is equal to $\frac{1}{2}\left(\frac{\partial v}{\partial x}-\frac{\partial u}{\partial y}\right)$.

- The deviation of the torsional rotation of the normal from that of the surface is assumed to have the governing strain energy [10]:

$$
U_{t}=\alpha_{t} \cdot G \cdot h \iint_{A}\left[\alpha_{3}-\frac{1}{2}\left(\frac{\partial v}{\partial x}-\frac{\partial u}{\partial y}\right)\right]^{2} \quad d A
$$

Where $\left(\alpha_{t}\right)$ is known as torsional coefficient. The $\operatorname{Eq}(11)$ will play the role of penalty function results in the desired constraint at the Gauss points as:

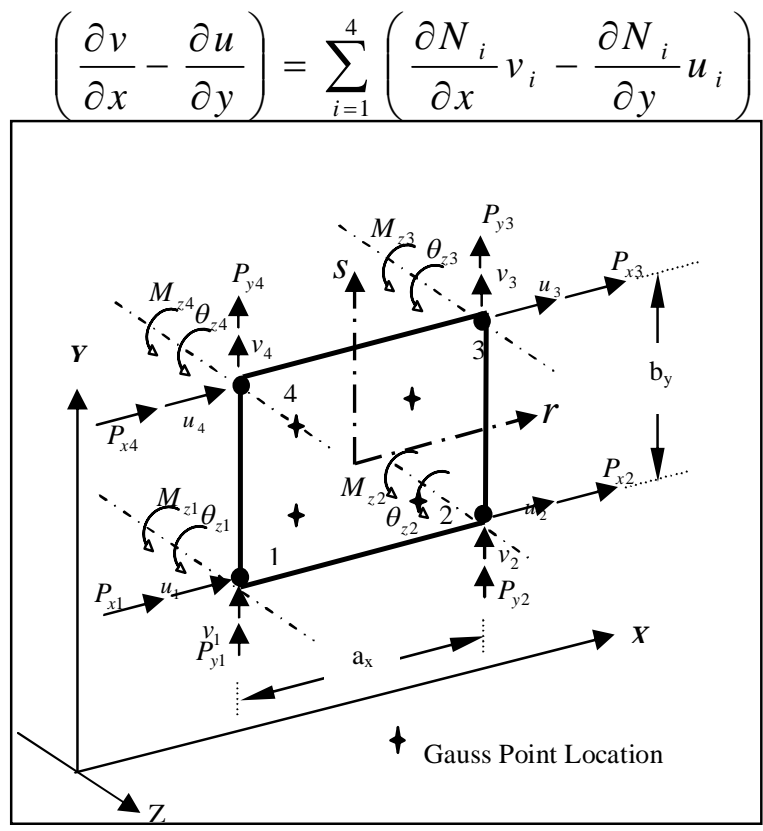

Fig.(2):Modified plane stress element (3DOF for each node)

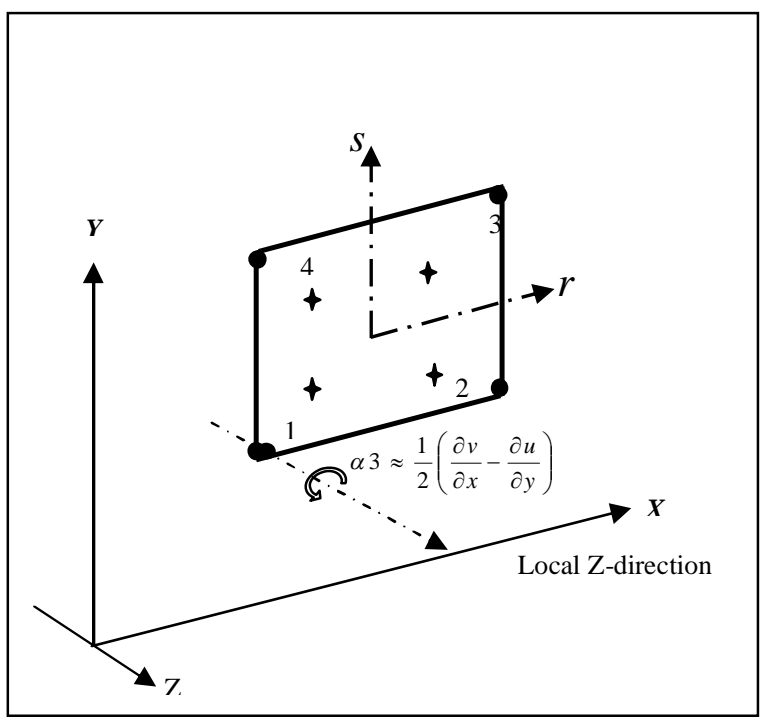

Fig.(3):Drilling degree of freedom 
The strain energy $\left(U_{t}\right)$ can be expressed in terms of the stiffness that is related to the drilling degrees of freedom as:

$U_{i}=\{a\}^{T}\left[K_{t}\right]\{a\}$

By substituting $\mathrm{Eq}(12)$ in $\mathrm{Eq}(11)$ and using $\mathrm{Eq}(13)$ the torsional stiffness can be expressed as:

$$
\left[K_{t}\right]=\alpha_{t} \cdot G \cdot h \int_{-1}^{+1} \int_{-1}^{+1} R_{e}{ }^{T} R_{e}|J| d r d s
$$

where

$\alpha_{t}=$ drilling coefficient.

$G=$ shear modulus

$h=$ thickness of the element

$$
\begin{aligned}
& R_{e}=\left[\begin{array}{llll}
R_{e 1} & R_{e 2} & R_{e 3} & R_{e 4}
\end{array}\right] \\
& R_{e i}=\left[\begin{array}{llll}
\frac{1}{2} \cdot \frac{\partial N_{i}}{\partial y} & -\frac{1}{2} \cdot \frac{\partial N_{i}}{\partial x} & N_{i}
\end{array}\right]^{T}
\end{aligned}
$$

The test of this element indicates that the addition of drilling stiffness will not degrade the behaviour of the system. The resulting drilling stiffness matrix is added to the original matrix of plane stress element determined in Eq.(10). Failure criterion with a tension cut off as shown in Fig.(4) was adopted to predict cracking, in which the stiffness normal to crack is reduced to zero, but along the crack partial shear stiffness is maintained to take into account the partial force transfer due to interlocking between the two faces of the crack. (see Fig.(5)). While in compression when equivalent strain attains crushing strain, the point is assumed to crush and the stiffness and all stresses at that point are reduced to zero.

\section{3: Frame- Infill Interface Element:}

The behavior of infilled frame depends upon the interaction between the infill and the frame. There can be separation, closing of gap and slipping between the frame and the infill. A two noded linkage element as shown in Fig.(1) was used to model this behavior between the frame and the panel elements with 3-DOF per nodes $\left(u, v, \theta_{z}\right)$. The stiffness matrix in local coordinates of the linkage element can be expressed as:

$$
\left[K_{i e}\right]=\left[\begin{array}{cccccc}
k_{n} & 0 & 0 & -k_{n} & 0 & 0 \\
0 & k_{s} & 0 & 0 & -k_{s} & 0 \\
0 & 0 & k_{\theta} & 0 & 0 & -k_{\theta} \\
-k_{n} & 0 & 0 & k_{n} & 0 & 0 \\
0 & -k_{s} & 0 & 0 & k_{s} & 0 \\
0 & 0 & -k_{\theta} & 0 & 0 & k_{\theta}
\end{array}\right]
$$

This stiffness matrix is transformed to the global coordinates by using transformation process which will lead to the following explicit form of the stiffness matrix:

$$
\left[K_{\mathrm{int}}\right]=\left[\begin{array}{cccccc}
C_{X}{ }^{2} k_{n}+C_{Y}^{2} k s & C_{X} C_{Y} k_{n}-C_{X} C_{Y} k s & 0 & -C_{X}{ }^{2} k_{n}-C_{Y}{ }^{2} k s & -C_{X} C_{Y} k_{n}+C_{X} C_{Y} k s & 0 \\
C_{X} C_{Y} k_{n}-C_{X} C_{Y} k s & C_{Y}{ }^{2} k n+C_{X}{ }^{2} k_{s} & 0 & -C_{X} C_{Y} k_{n}+C_{X} C_{Y} k s & -C_{Y}{ }^{2} k n-C_{X}{ }^{2} k_{s} & 0 \\
0 & 0 & k_{\theta} & 0 & 0 & -k_{\theta} \\
-C_{X}{ }^{2} k_{n}-C_{Y}{ }^{2} k s & -C_{X} C_{Y} k_{n}+C_{X} C_{Y} k s & 0 & C_{X}{ }^{2} k_{n}+C_{Y}{ }^{2} k s & C_{X} C_{Y} k_{n}-C_{X} C_{Y} k s & 0 \\
-C_{X} C_{Y} k_{n}+C_{X} C_{y} k s & -C_{Y}{ }^{2} k n-C_{X}{ }^{2} k_{s} & 0 & C_{X} C_{Y} k_{n}-C_{X} C_{Y} k s & C_{Y}{ }^{2} k n+C_{X}{ }^{2} k_{s} & 0 \\
0 & 0 & -k_{\theta} & 0 & 0 & k_{\theta}
\end{array}\right]
$$


Where Cx, Cy are defined in Fig.(1).
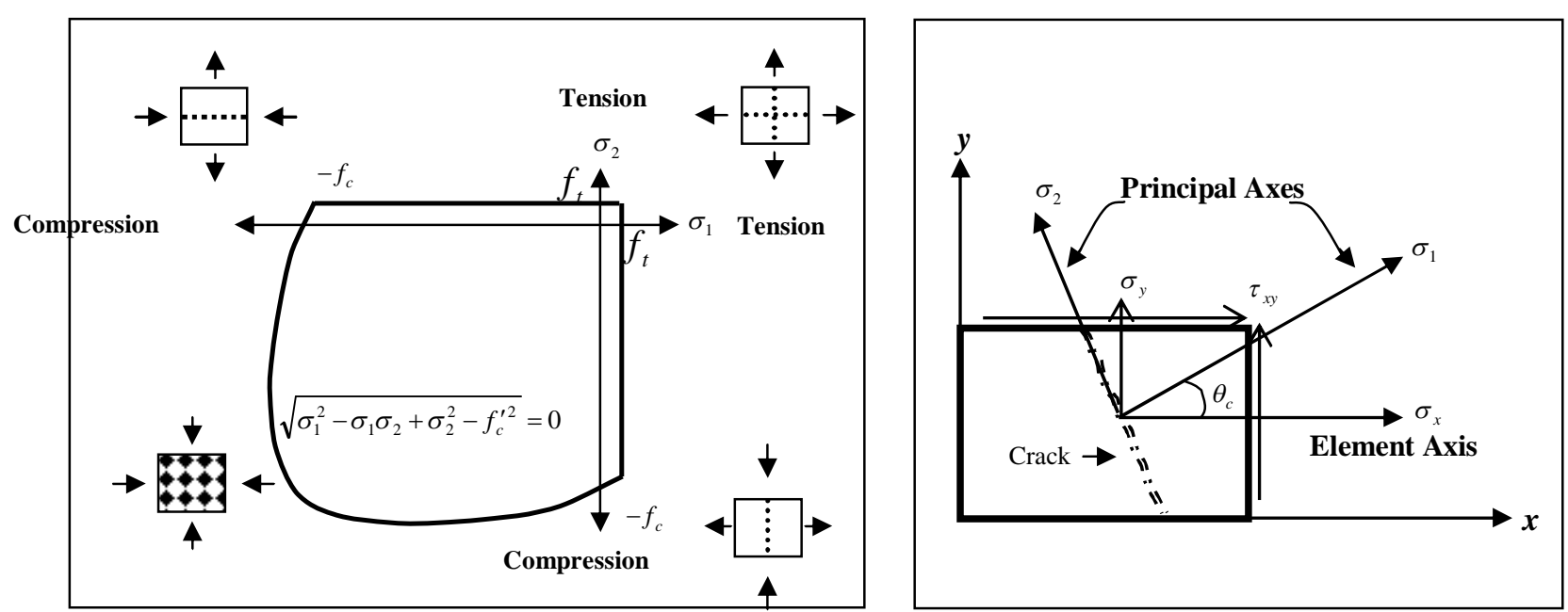

Fig.(4):Yield surface for the masonry panel. Fig.(5):Crack and principle axes direction

\section{3: Inelastic Analysis:}

This adopted model depends on the concept of Plastic Hinges, which reflect the inelastic behavior of the frame element, where each frame element is represented by the elastic part and assuming that the inelastic action is lumped at both ends of the frame element as plastic hinges. For each frame element, depending on the dimensions of the cross section, its physical properties, amount of reinforcement and its location, an interaction diagram between axial forces and moments is determined; this diagram is considered as Yield Surface which represents the limit of the ultimate strength of the element. The behavior of each frame element is assumed to be elastic until the force exceeds the yield surface at one or both ends of the element. In this case, the plastic hinges are assumed to develop and that element enters the stage of plastic deformation. To maintain compatibility in the degrees of freedom of the infilled elements (plane stress) and frame elements (beam-column), a Drilling Degree of Freedom is added to the original plane stress elements. The nonlinear behavior of the plane stress element is checked at the four $(2 \times 2)$ Gauss points. Plastic model is adopted, which is based on a yield criterion and flow rule. Cracking and crushing are also checked [6]. Both Perfect Bond between infill and surrounded concrete frame is used when the frame is filled with solid concrete walls, and Linkage Elements is used to connect the weak infilled elements (brick, masonry) and the surrounding concrete frame. Based on the developed forces in these elements, separation or slip between infill and frame is assumed to occur. Two computer programs have been developed using (Fortran-77). First one: for the elastic and inelastic static analysis of structures (plane stress problems, bare frames, frames with shear walls, frames with infilled panels). Increment-Iteration technique is adopted to predict the nonlinear response of the plane frame structures. The second program: for the elastic and inelastic dynamic analysis of structures (plane stress problems, bare frames, frames with shear walls, frames with infilled panels). A Direct Step-by-Step integration technique has been used in the dynamic analysis based on Newmark's Predictor-Corrector method [12,13] method to solve the equation of motion of the structure. Convergence is assumed when the ratio of the norms of unbalanced load to the norms of the total load is within the permissible limits, and the converged tolerance is taken equal to $(2 \%)[14]$. 


\section{4: Numerical Examples:}

To check the validity of the developed models and to study the behavior of reinforced concrete frames infilled with masonry panels subjected to static and dynamic loads, three structures have been analyzed. Two of these structures are used to examine the validation of the modified plane stress element in the static and dynamic analysis, and the third one is infilled frame.

\section{1: Single Beam Analysis:}

A single beam having cross section $(250 \mathrm{~mm} * 400 \mathrm{~mm})$ and $(2400 \mathrm{~mm})$ simple span as shown in Fig.(6) is analyzed statically using SAP(2000) software, adopting six elements taking into consideration two different cases:

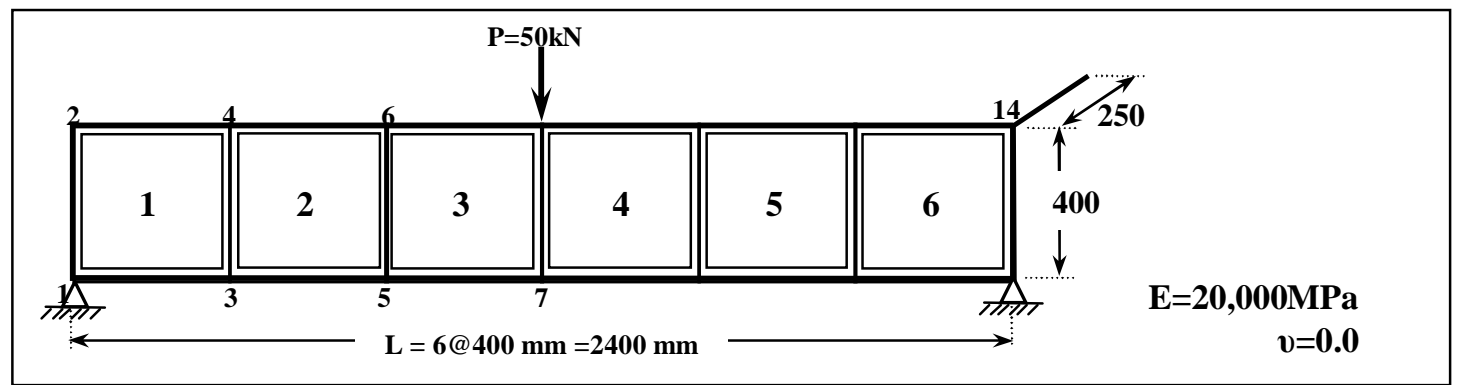

Fig.(6): Idealized beam (Beam-1)

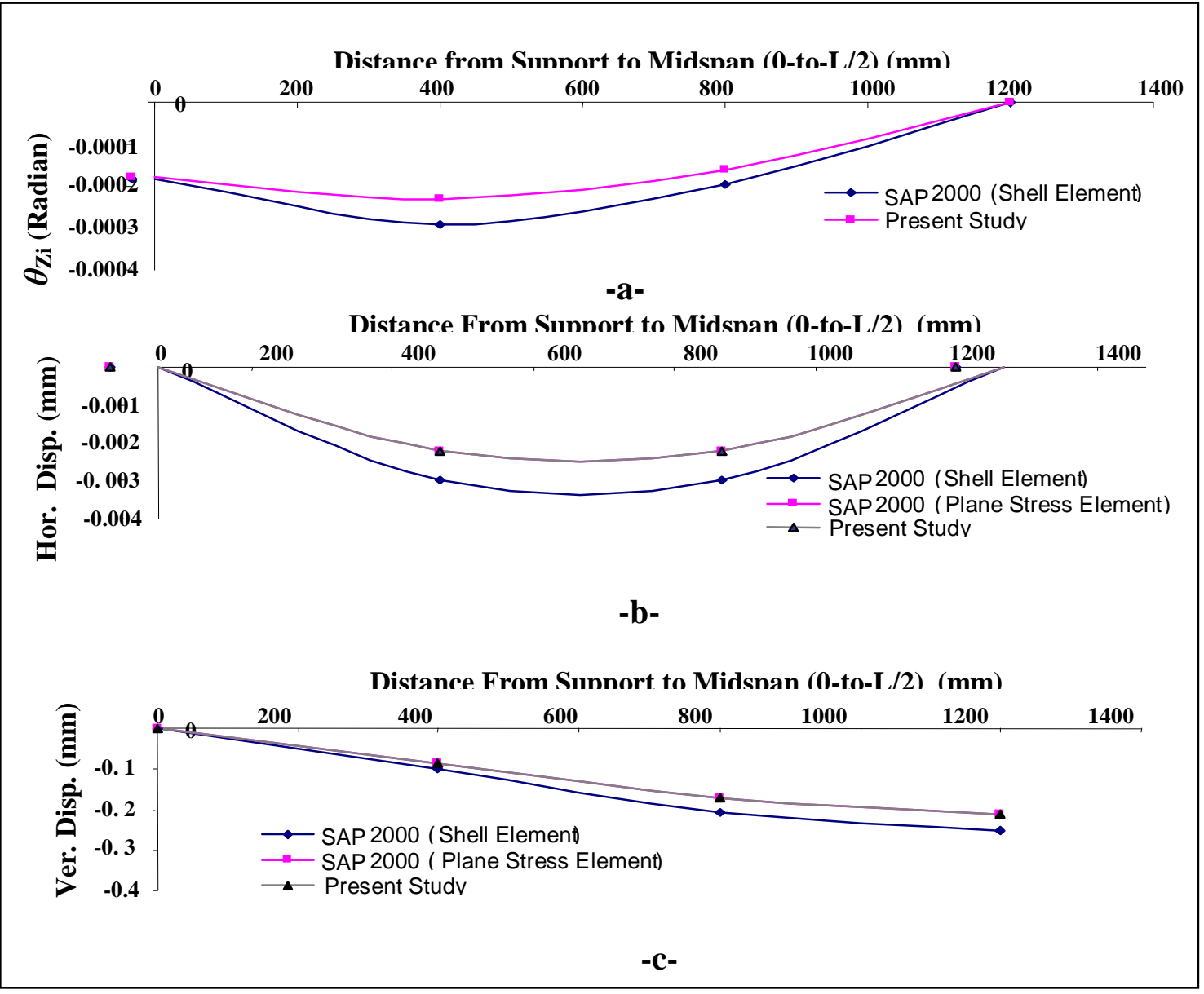

Fig.(7): a.comparation for drilling degree of freedom $\left(\theta_{\mathrm{Zi}}\right)$, b. comparation for the horizantel deoree of freedom (u;). c. comnaration for vertical degree of freedom $(v i)$. 
$i$. using 4-noded (plane stress element) with two degrees of freedom per node.

ii. Using 4-noded (shell element) having six degrees of freedom per node and restraining the degrees of freedom $\left(\omega, \theta_{x}, \theta y\right)$. The physical and material properties and other details of the beam are also given in the same figure. The deformation from support to midspan predicted by using the developed model is compared with that obtained by using SAP(2000) in Fig.(7). The plotted results are for the lower nodes. A good agreement is observed and needs no more comments.

\section{2: Dynamic Analysis of Cantilever Beam:}

Five modified plane stress elements are used to model the cantilever beam subjected to the load shown in Fig.(8), which also shows another idealization by using single beamcolumn element as shown in Fig.(8-d), the predicted results are compared with that from SAP2000.

The analysis using SAP2000 is carried out using two different idealizations. In the first one by using 4-node plane stress elements (2DOF); while in the second case by using 4-node (6DOF) shell elements with restraining $\left(\omega, \theta_{x}, \theta_{y}\right)$ are used. The beam is analyzed under the suddenly applied point load which is vanished gradually within 10 msec. Fig.(9) shows comparison between the predicted vertical deflection at the free end (point-A) using the developed model of the present study (both elastic and inelastic analysis), with the elastic results predicted by SAP2000. The matching between the predicted results using present formulation of 4-node plane stress element or single beam-column element (elastic analysis) with that of SAP2000 is quite clear.

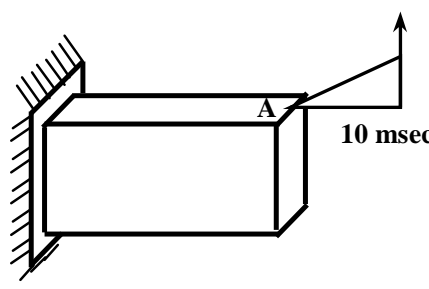

(a): Cantilever-1
$150 \mathrm{kN}$

$\mathrm{E}=30,000 \mathrm{MPa}$

$\Delta \mathrm{t}=\mathbf{0 . 0 0 0 0 5} \mathrm{sec}$ $\zeta=5 \%$

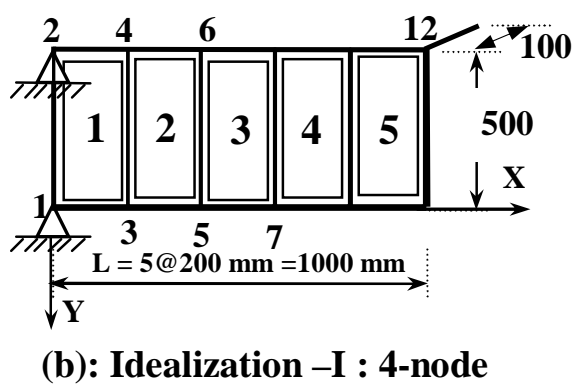

2-DOF Plane Stress Element

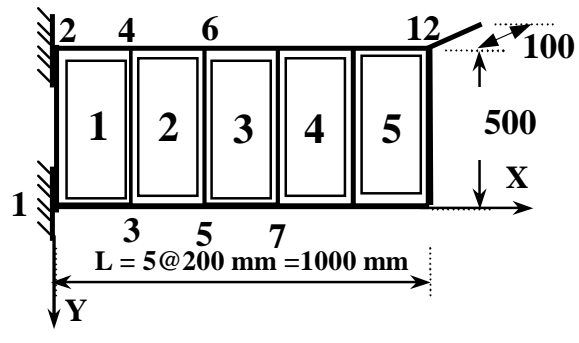

(c): Idealization -II : 4-Node, 3DOF Shell Element or Modified Plane Stress Element

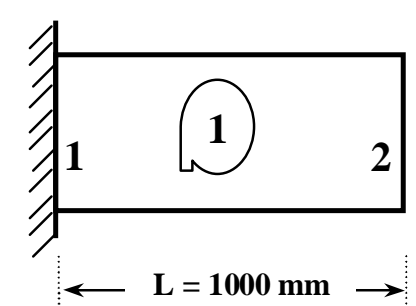

(d): Idealization -III : 2-Node, 3-DOF Beam-Column Element

\section{Fig.(8): Cantilever beam under dynamic load}

As can also be seen in Fig.(9-b) that when the inelastic behaviour of the material is taken into consideration, this will cause a residual displacement and this can be attributed to the cumulative plastic deformation in the elements of the structure. 
Fig.(10) shows comparison of rotation $\theta_{z}$ predicted by the developed model with that of SAP2000. The figure shows a good agreeable matching between the results of shell element with that of the developed plane stress element with drilling degree of freedom.

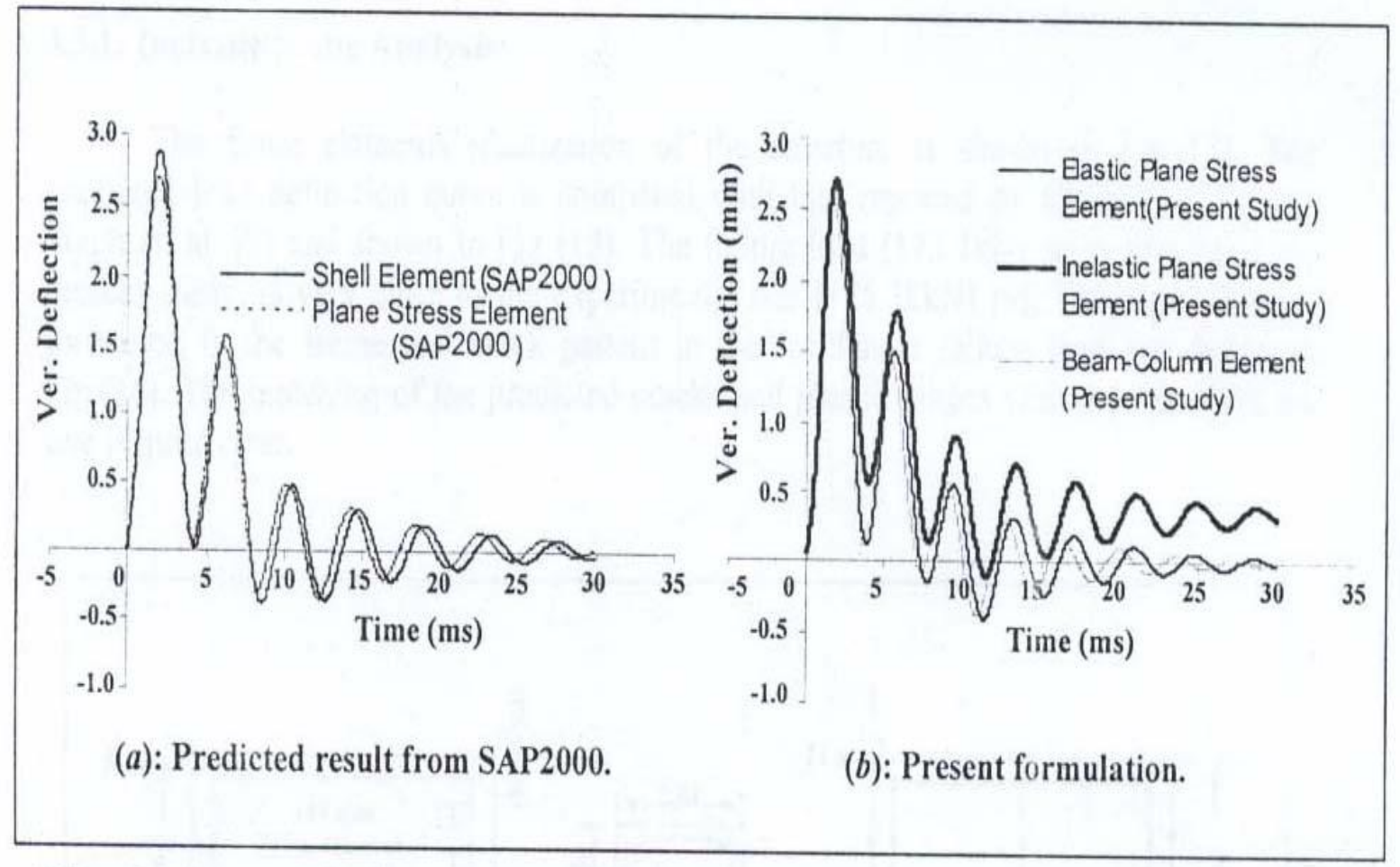

Fig.(9): Comparison of predicted results with SAP2000 for vertical deflection at the free end.

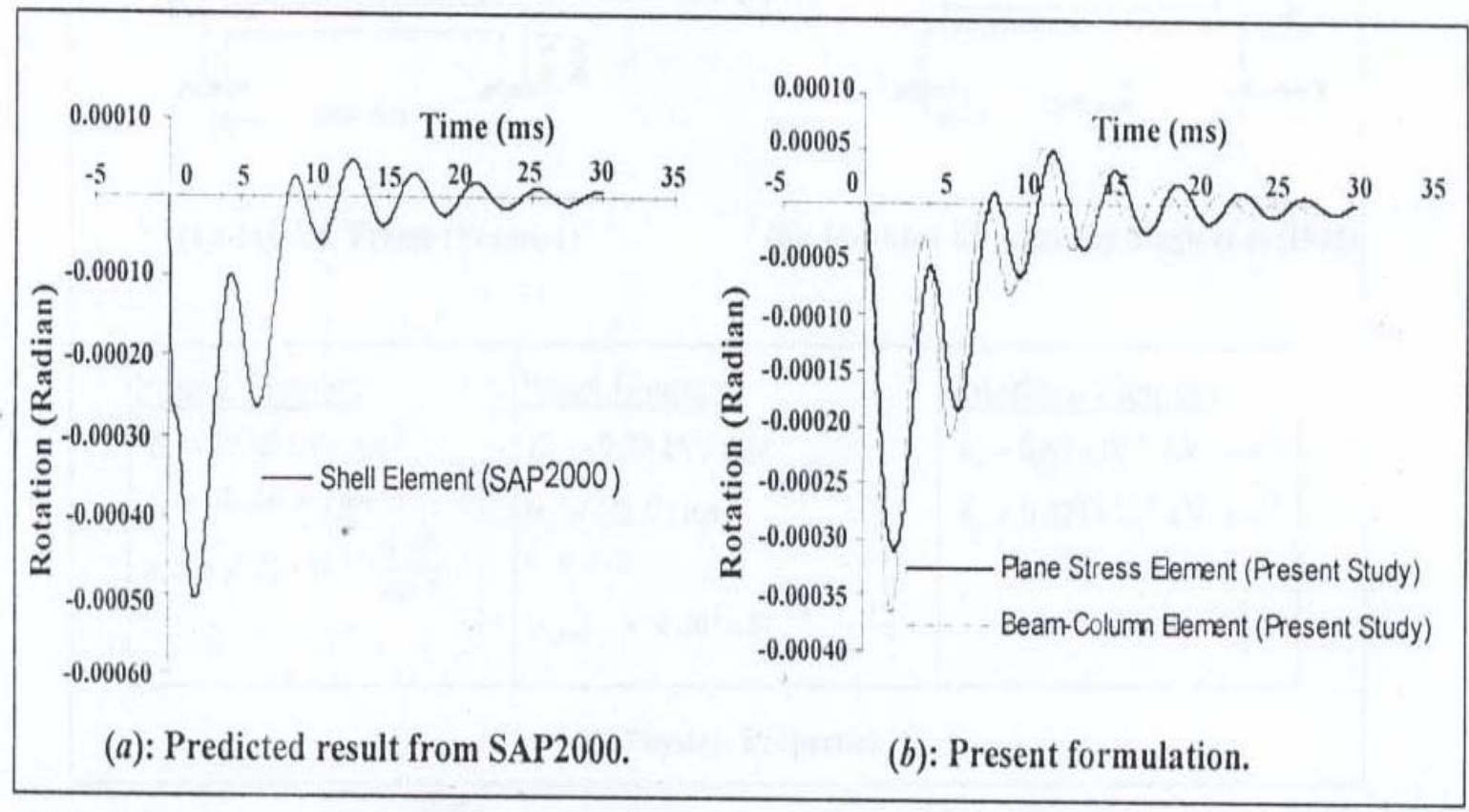

Fig.(10): Comparison of predicted results with SAP2000 for $\theta z$ at the free end. 


\section{3: Reinforced Concrete Infilled Frame:}

A single-story one bay reinforced concrete frame infilled with masonry wall, having the details shown in Fig.(11) is analyzed under static and dynamic loads. This frame has been tested by Choubey [15] under static point load applied as shown in the same figure, and analyzed under dynamic load by Singh et. al. [9].

\subsection{1: Inelastic Static Analysis:}

The finite elements idealization of the structure is shown in Fig.(12). The predicted load deflection curve is compared with that reported by Choubey [15], and Singh et. al. [9] and shown in Fig (13). The failure load $(173.7 \mathrm{kN})$, as predicted in the present study, is very close to the experimental one $(175.38 \mathrm{kN})$ [9]. The plastic hinges formation in the frame and crack pattern in the infill near failure load are shown in Fig.(14). The matching of the predicted cracks and plastic hinges with the experimental one is quite clear.

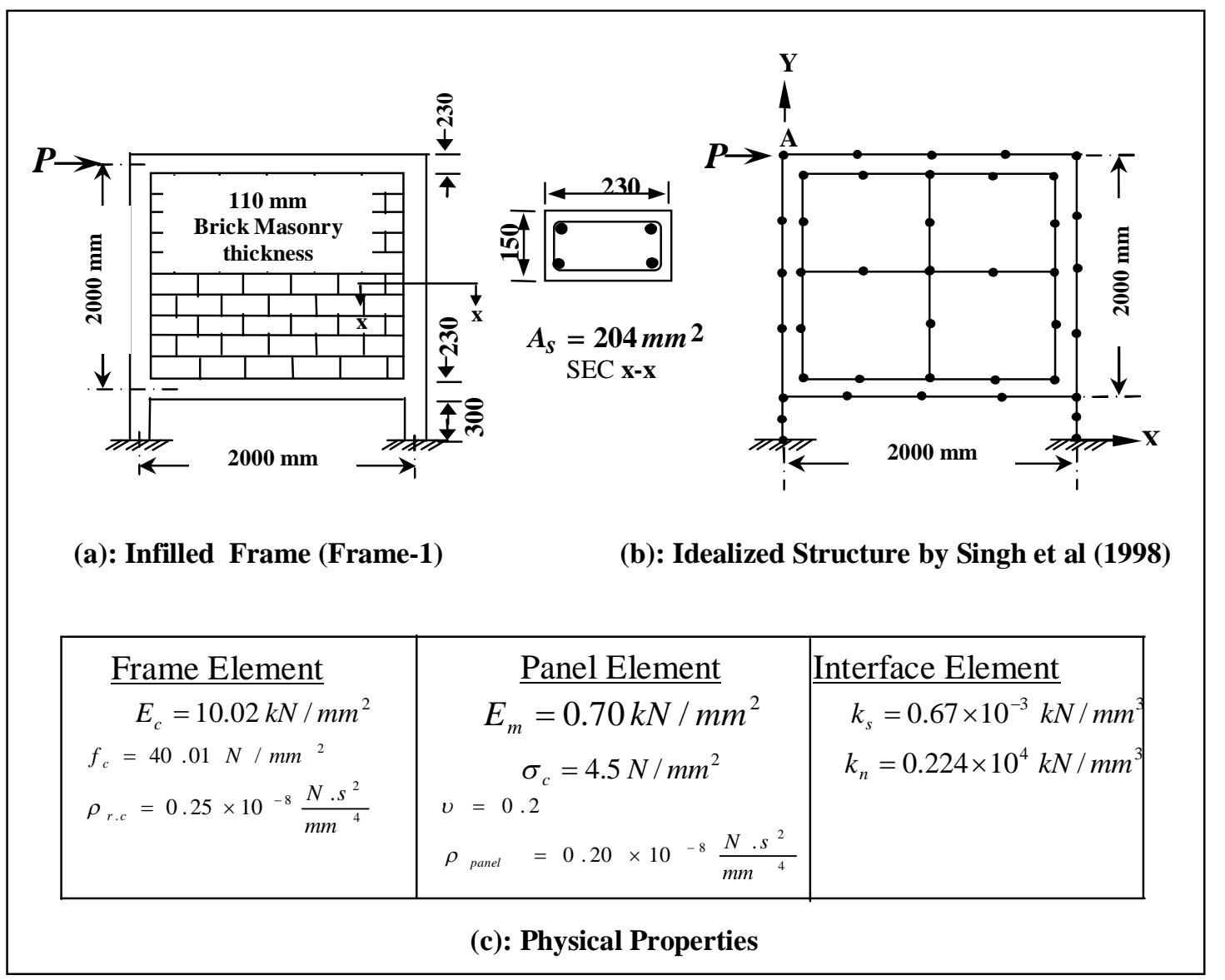

Fig.(11): Infilled frame (frame-1).

Fig.(13) also shows that by neglecting the interface between the frame and infilled wall, by assuming perfect bond between them, the response of the structure significantly deviates from the actual (experimental) results, and the predicted failure load is only (101.3 $\mathrm{kN}$ ) 


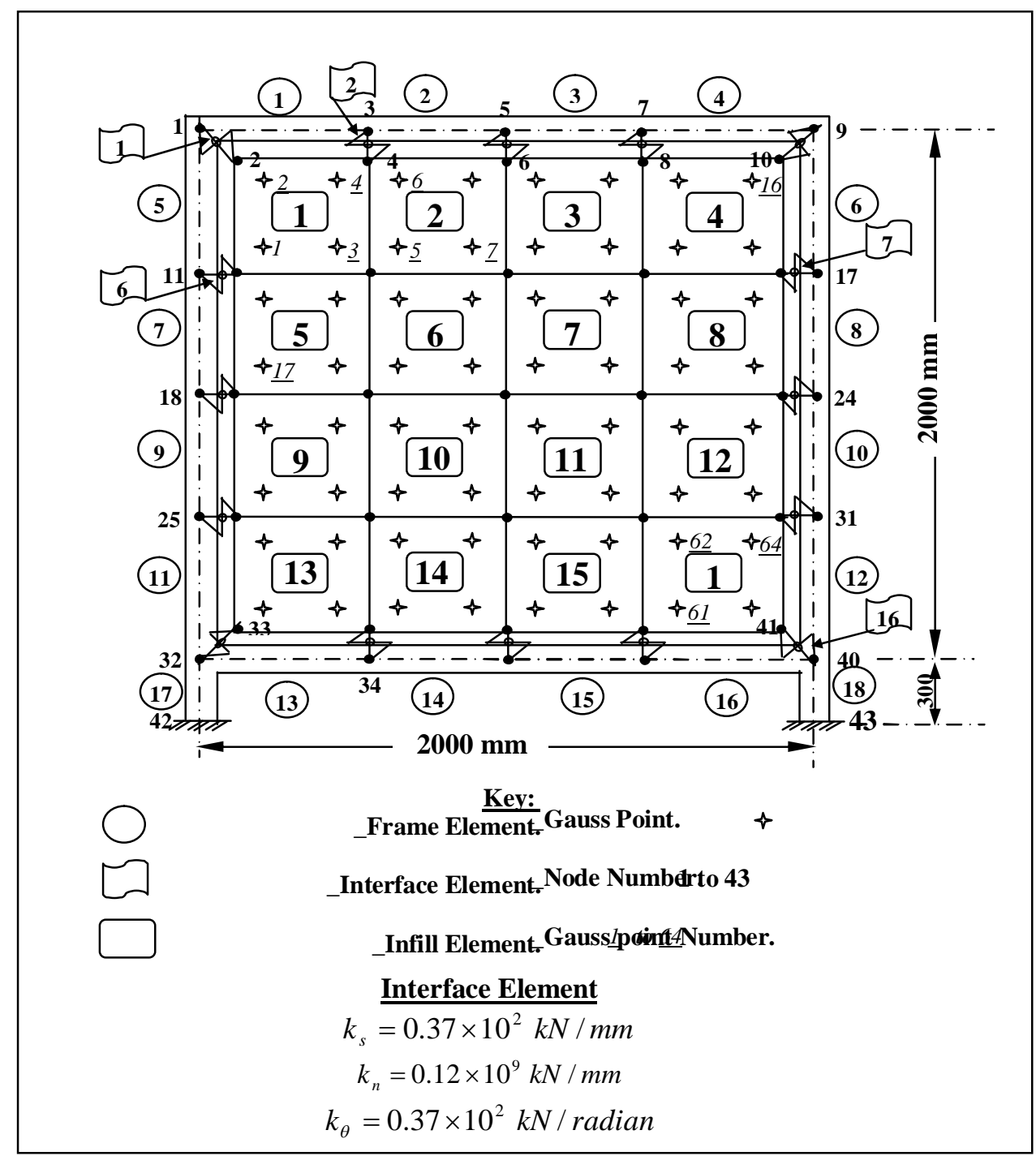

Fig.(12): Idealized Structure (Frame-1).

\subsection{2: Elastic and Inelastic Dynamic Analysis:}

The same frame (frame-1) is analyzed also dynamically under the effect of triangle load at (0.4 sec.) duration, and applied as shown in Fig.(15). Three cases of analysis are considered:

i. Elastic analysis neglecting the infilled wall.

ii. Inelastic analysis neglecting the infilled wall.

iii. elastic analysis considering the interaction of the frame with the infilled wall.

iv. Inelastic analysis considering the interaction of the frame with the infilled wall.

Fig.(16) shows the comparison between the above three different cases, and the following can be stated:- 
Mahmood: Effect of Infilled Panel on the Nonlinear Dynamic Response of Reinforced

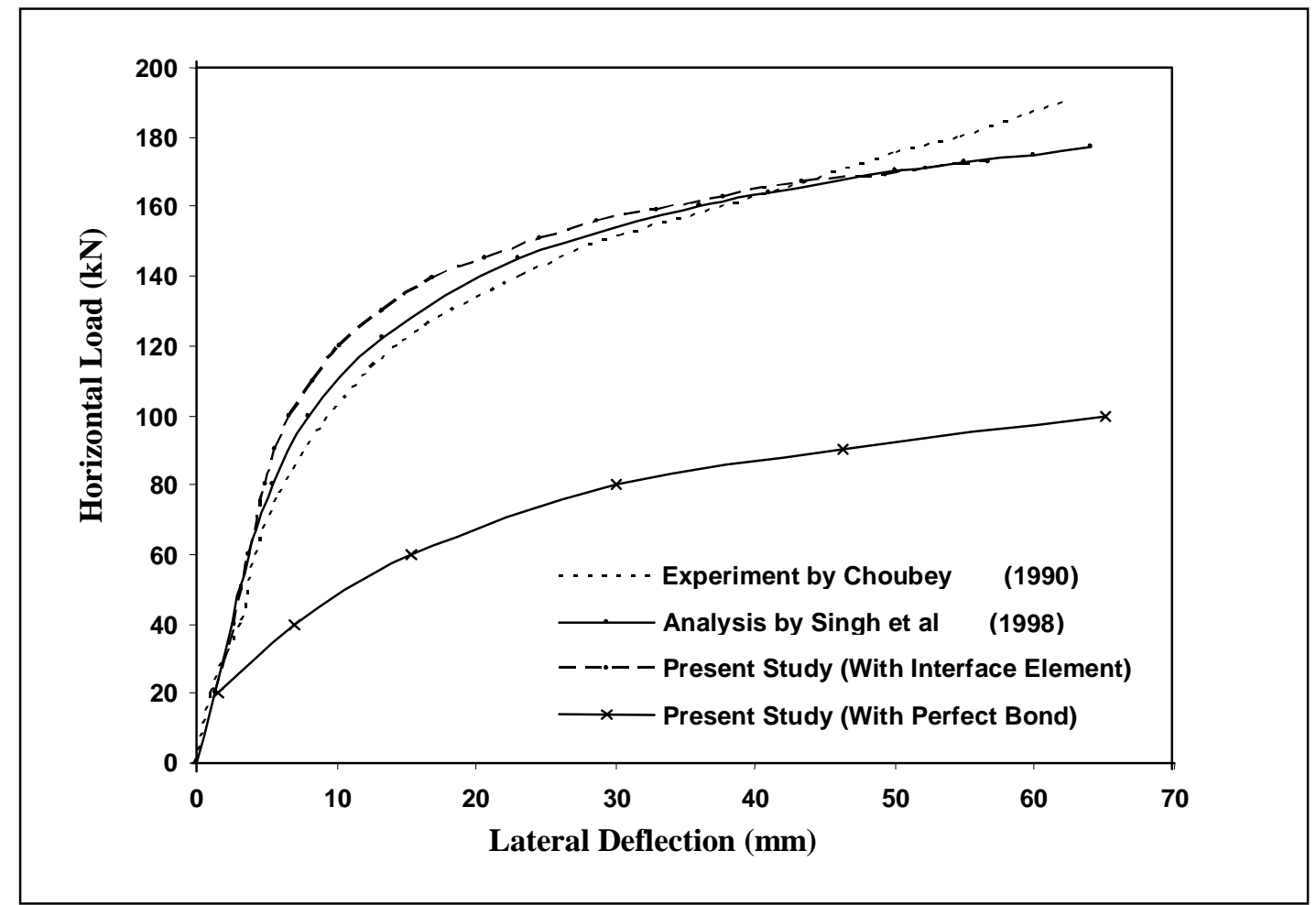

Fig.(13): Horizontal load-deflection curve at node -A-

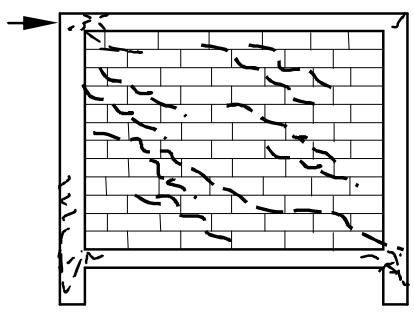

(a): Crack Pattern (Choubey (100ก)

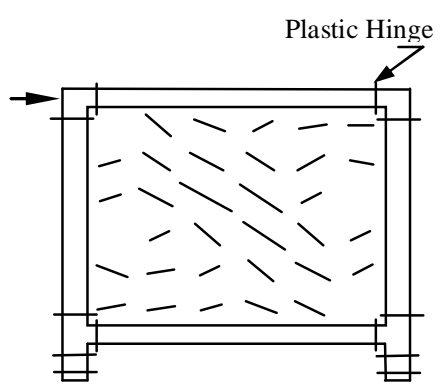

(b): Crack Pattern (Singh (1998))

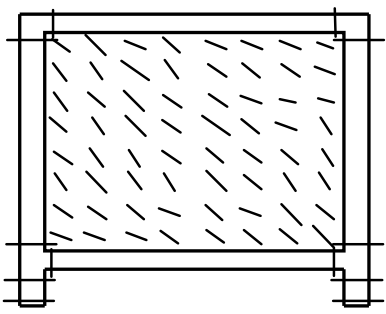

(c): Crack Pattern (Present Study)

Fig.(14): Plastic hinges and crack pattern in (frame-1) at failure load

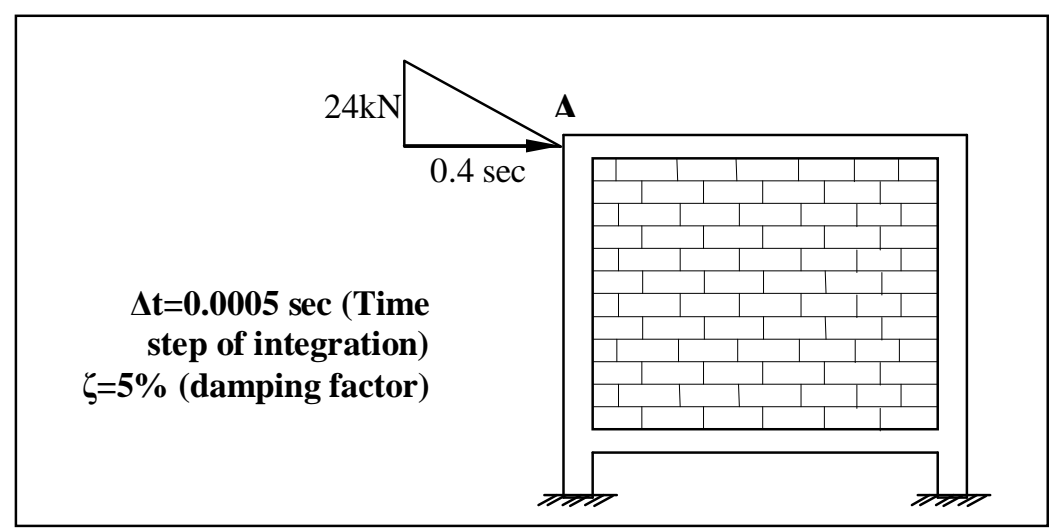

Fig.(15): Dynamic Load effecting on (frame-1) 


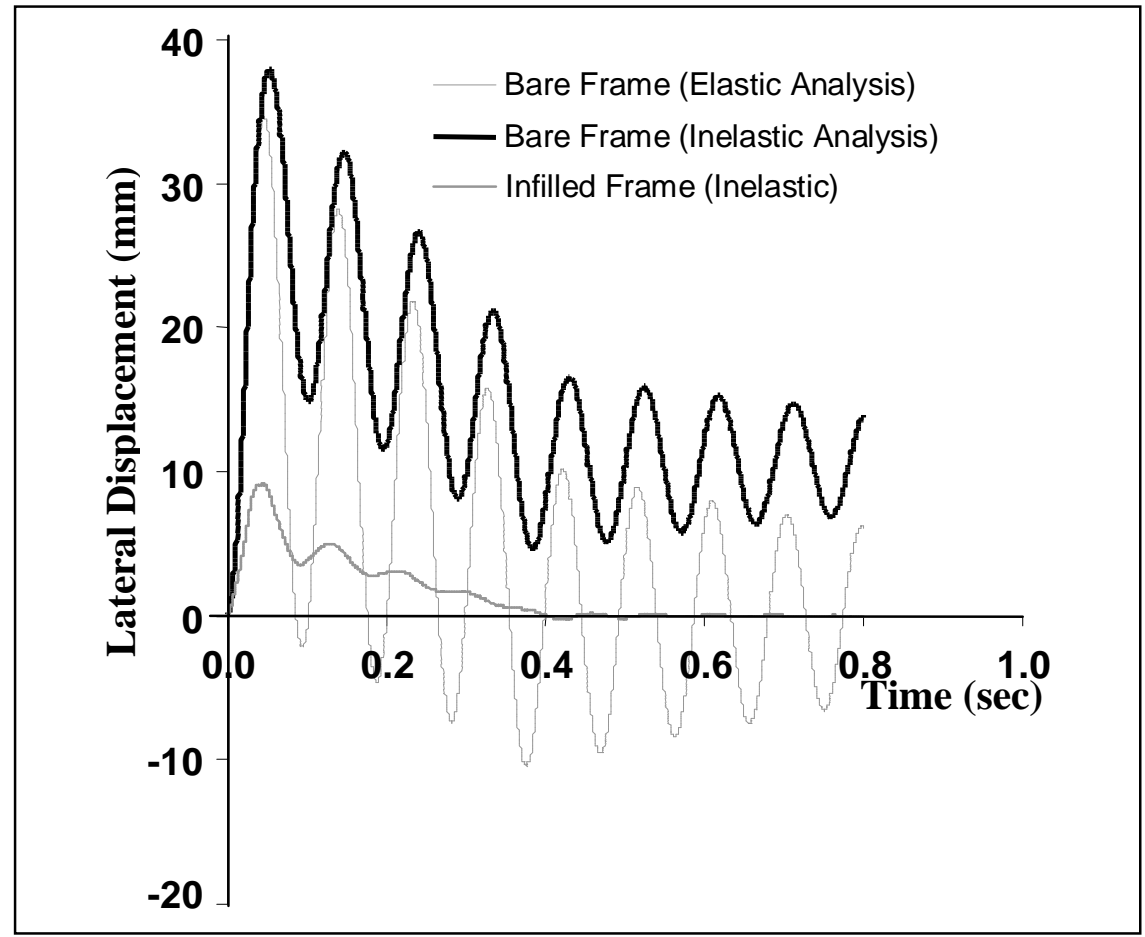

Fig.(16): Dynamic Response in terms of lateral deflection at node (A).

$>$ There is a significant difference between the elastic and inelastic response of the bare frame, especially after the ends of load application (free vibration stage), and that is due to the plastic deformation resulting from the formation of plastic hinges. Table (1) shows the locations and stages of formation of plastic hinges in the frame.

The maximum horizontal deflection of point $(\mathrm{A})$ was $(34.7 \mathrm{~mm})$ from elastic dynamic analysis, $(37.9 \mathrm{~mm})$ from inelastic analysis, and $(9.18 \mathrm{~mm})$ for infilled frame (inelastic analysis) and this indicates that the infill enhances the dynamic response of the frame. Table (2) shows the time at which these maximum displacements occur.

$>$ No plastic hinges developed in the infilled frame. Some tension cracks developed in the panel and they are enclosed in the advanced stages.

No residual deflection occurred in the infilled frame at the end of load duration.

Table (1): Sequences of forming plastic hinges and it is locations

\begin{tabular}{|c|c|c|c|c|}
\hline \multirow[t]{2}{*}{ Hinge No. } & \multirow{2}{*}{$\begin{array}{l}\text { Time } \\
\text { (sec) }\end{array}$} & \multicolumn{3}{|c|}{ Remarks } \\
\hline & & $\begin{array}{l}\text { Load } \\
\text { Duration }\end{array}$ & 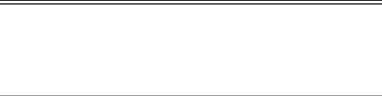 & $\begin{array}{l}24.0 \mathrm{kN} \\
0.4 \mathrm{sec}\end{array}$ \\
\hline 1 & 0.02850 & & \multirow[t]{2}{*}{ Plastic Hinge Location } & \\
\hline 2 & 0.03250 & & & \\
\hline 3 & 0.03350 & & & \\
\hline 4 & 0.04800 & & & \\
\hline 5 & 0.05250 & & & \\
\hline
\end{tabular}


Table (2): Times at which maximum deflection occurs.

\begin{tabular}{|c||c|c|c||c||}
\hline \multirow{2}{*}{ Frame Type } & \multicolumn{2}{|c|}{ Elastic } & \multicolumn{2}{c||}{ Inelastic } \\
\cline { 2 - 5 } & $\begin{array}{c}\text { Max. Lateral } \\
\text { Deflection } \\
(\mathrm{mm})\end{array}$ & $\begin{array}{c}\text { Time } \\
(\mathrm{sec})\end{array}$ & $\begin{array}{c}\text { Max. Lateral } \\
\text { Deflection } \\
(\mathrm{mm})\end{array}$ & $\begin{array}{c}\text { Time } \\
\text { (sec) }\end{array}$ \\
\hline \hline Bare frame & 34.7 & 0.0455 & 37.9 & 0.0530 \\
\hline \hline Infilled frame & 8.27 & 0.0405 & 9.18 & 0.0435 \\
\hline
\end{tabular}

\section{5: Conclusions:}

1. The validation of the modified 4-node plane stress element with drilling degree of freedom has shown a stable and a good agreement with the results predicted by SAP200 program using 4-node shell elements.

2. The inelastic dynamic analysis of bare frame gave higher maximum deflections and longer periods of vibrations as compared to the elastic response.

3. Including the infilled wall in the dynamic analysis significantly reduced the deformation of the frame in both elastic and inelastic analysis.

4. Interface between the frame and surrounding infill play an important role in the overall response of the structure compared with that of perfect bond.

5. Most of the plastic hinges developed in the frame elements in a very short time of dynamic load application and occurred in the first cycle of vibration.

6. Cracks in infilled panel elements occurred during a very short time of load application in the first cycle of vibration and these cracks closed after reflection of direction of vibration and continue to open and close during the vibration of the structure.

\section{References:}

1. Polyakov,s.v., "on the interaction between masonry filler walls and enclosing frame when loaded in the plane of the wall", Earthquake Engineering research Institute, San Francisco, Calif., pp.36-42, (1960).

2. Seah, C. K., Dawe, J. L., "Behaviour of masonry infilled walls", Proceedings of the $11^{\text {th }}$ International Brick/Block Masonry confrenece, Tongji University, Shanghai, China, pp.940-948, (1997).

3. Mehrabi, A. B. and Shing, P. B., "Finite Element Modeling of Masonry Infilled R/C Frames", J. of Struct. Engg. Div., ASCE, Vol.123, No. 5, pp.604-613, (1997).

4. Wood, R. H., "Plasticity Composite Action and Collapse Design of Unreinforced Shear Wall Panels in Frames", Proc. Instu. Civ. Engg. Part 2, pp. 381-411, (1978).

5. Medland, I. C. and Taylor, D. A., "Flexural Rigidity of Concrete Column Section", J. of Struct. Engg. Div., ASCE, Vol.97, No. ST2, PP.573-586, (1971).

6. Ahmed, Saddam. M., "effect of infilled panel on non linear dynamic analysis of plane frames", M.Sc. Thesis, Mosul University, Iraq, (2006).

7. Thanoon, W. A. and Al-sulyvani, B. J., "Mathematical Modeling of Non-Linear ThrustMoment-Curvature Relation of R/C Section" Al-Rafidain Engg. J., Vol.5, No.2, pp.1123, (1997).

8. Thanoon, W. A., "Inelastic Dynamic Analysis of Concrete Frames under Non-Nuclear Blast Loading", Ph.D. Thesis, University of Roorkee, India, (1993).

9. Singh, H., Paul, D. K. and Sastry, V. V., "Inelastic Dynamic Response of R/C Infilled Frames", Computer and Structures., Vol.69, pp.685-693, (1998). 


\begin{tabular}{llll} 
Al-Rafidain Engineering & Vol.17 & No.3 & June 2009 \\
\hline
\end{tabular}

10. Krishna Moorthy C. S., "Finite Element Analysis Theory and Programing", McGrawHill Publishing Company Limited, (1988).

11. Ali, S. S. and Page, A. W., "Finite Element Model for Masonry Subjected to Concentrated Loads", Journal of Structural Engineering Division, ASCE, Vol.114, No. ST8, pp.17611784, (1988).

12. Weaver, W. J. and Johnston, P. R., “Structural Dynamics by Finite Elements", PrenticeHall Inc., New Jersey, (1987).

13. Wilson, E. L., "Three-Dimensional Static and Dynamic Analysis of Structures", A Physical Approach with Emphasis on Earthquake Engineering, Computers and Structures, Inc., Berkeley, California, (2002).

14. Owen, D. R. J. and Hinton, E., "Finite Element in Plasticity: Theory and Practice", Pineridge Press Limited, Swansea, U.K, (1980).

15. Choubey, U.B., "Behavior of Infilled Frames under Cyclic Loads", Ph.D. Thesis Submitted to IIT Delhi, (1990). 